\title{
Analysis of the Structural State Formed in Titanium at the Final Severe Plastic Deformation Stage
}

\author{
O. I. Volchok ${ }^{a}$, V. V. Kalinovskii ${ }^{a}$, I. F. Kislyak ${ }^{a}$, I. V. Kolodii ${ }^{a}$, G. E. Storozhilov ${ }^{a}$, \\ N. V. Kamyshanchenko ${ }^{b}$ *, and A. V. Gal'tsev ${ }^{b}$ \\ ${ }^{a}$ Kharkov Institute of Physics and Technology National Scientific Center, Khar'kov, 61108 Ukraine \\ ${ }^{b}$ Belgorod State University, Belgorod, 308015 Russia \\ *e-mail:kamysh@bsu.edu.ru
}

Received April 30, 2020; revised June 1, 2020; accepted June 2, 2020

\begin{abstract}
The structural state of iodide titanium after deformation by drawing at $77 \mathrm{~K}$, which is the final stage of severe plastic deformation (SPD), has been analyzed and estimated in this work. The SPD has been implemented by a sequential combination of deformation techniques (compression-squirting-extrusion-drawing) that provide different stress epures. The temperature dependence of the logarithmic damping decrement of torsional oscillations in the 77-250 K temperature range has been studied to give a physical interpretation of the nonmonotonic change in the strength of the iodide titanium after SPD and to compare the calculated strength with that obtained for low purity titanium.
\end{abstract}

Keywords: severe plastic deformation, drawing, internal friction, damping, strength, structural defects

DOI: $10.1134 / \mathrm{S} 0031918 \mathrm{X} 20090100$

\section{INTRODUCTION}

Deformation-induced refinement is one of the main trends in the production of bulk metallic nanostructured materials which can be implemented using severe plastic deformation (SPD) [1]. Despite the existence of complicated SPD schemes (e.g., equalchannel angular pressing, isothermal forging, screw extrusion, and others [1-3]), we have shown for the first time that SPD, which can be used to create nanostructural materials, can be achieved by a sequential combination of deformation techniques that provide different stress epures (compression-squirting-extrusion-drawing) [4-9]. Deformation by drawing carried out at the final stage under cryogenic conditions $(77 \mathrm{~K})$ is an additional and important factor in structural refinement.

The aim of this work is to analyze and estimate the structural states of titanium that determine its mechanical properties depending on the deformation degree (drawing at $77 \mathrm{~K}$ ). This dependence was previously revealed in [6] by the authors of this paper.

\section{EXPERIMENTAL}

After electron-beam remelting in a vacuum of $1.3 \times$ $10^{-3} \mathrm{~Pa}$, an ingot of iodide titanium was deformed according to the compression-extrusion-drawing scheme. Compression and extrusion were performed at $800 \mathrm{~K}$ (true strain $e=3.6$ ). The rod extruded $10 \mathrm{~mm}$ in diameter was then deformed by drawing to obtain a diameter of $3.75 \mathrm{~mm}(e=2)$. The rod after the preliminary drawing was cut into two parts by the electric spark technique. One part of the rod was finally deformed by drawing in liquid nitrogen $(77 \mathrm{~K})$ and another was deformed at $300 \mathrm{~K}$ for comparison. The drawing under cryogenic conditions was carried out using special equipment described in detail in [10].

To analyze and estimate the structural state of titanium after the final stage of drawing, we measured the temperature dependence of the logarithmic damping decrement $\delta(T)$ of the torsional oscillations of lowfrequency $(0.5 \mathrm{~Hz})$ internal friction in the $77-250 \mathrm{~K}$ temperature range using a reverse torsion pendulum in the heating mode with temperature stabilization (heating rate $0.025 \mathrm{~K} / \mathrm{s}$, measurement time of the damping decrement $150 \mathrm{~s}$, vacuum $1.3 \times 10^{-3} \mathrm{~Pa}$ ) in the amplitude-independent region (strain amplitude $\left.8 \times 10^{-8}\right)$. Wire samples of at least $0.5 \mathrm{~mm}$ in diameter and $40 \mathrm{~mm}$ long were used. The measurement of $\delta(T)$ was performed on the samples after the final stage of SPD by drawing at 77 and $300 \mathrm{~K}$ at two true strains $\left(e_{1}=0.92, e_{2}=1.45\right)$, corresponding to the extremum points of the microhardness-true strain dependences $H_{\mu}(e)$ calculated in [6]. Each experimental $\delta(T)$ curve is, as will be shown below, peak-shaped. This allowed each peak to be decomposed into components via computer calculation. The applied technique made it possible to calculate the activation energy of the processes and, consequently, to analyze the structural state of the titanium after different drawing stages. The 


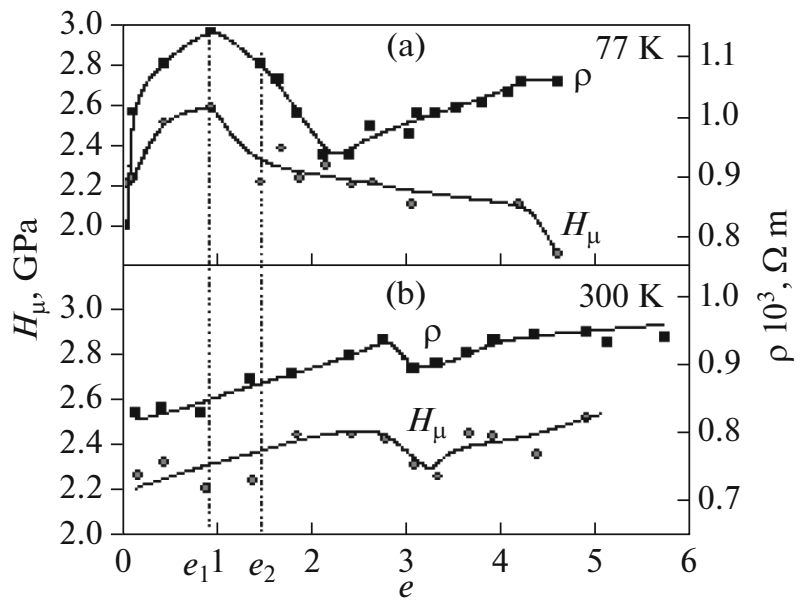

Fig. 1. Microhardness and electrical resistivity of titanium as a function of the true strain achieved by drawing at (a) 77 and (b) $300 \mathrm{~K}$.

activation energy was calculated using the Wert-Marx formula [11]:

$$
U=R T \ln \left(\frac{k T}{h f}\right)
$$

where $T$ is the temperature at which the internal friction maximum is observed, $f$ is the measuring frequency, $R$ is the gas constant, $k$ is the Boltzmann constant, and $h$ is the Planck constant.

\section{RESULTS AND DISCUSSION}

The investigation carried out in [6] showed that drawing at $77 \mathrm{~K}$ at the final stage of the SPD by compression-extrusion-drawing resulted in the nonmonotonic true-strain dependence of the microhardness and electrical resistivity (Fig. 1 ). At $e \approx 0.92$, there is a sharp increase in the microhardness and electrical resistivity, which indicates a significant increase in the concentration of deformation defects and, accordingly, an increase in the internal stress level. Further deformation by drawing at $77 \mathrm{~K}$ to $e>0.92$ leads to a drop in the microhardness, which can be explained by internal stress relaxation due to the opening of microcracks formed from pores that have formed during vacancy coalescence. We should note that the probability of this process is high because vacancies form due to the intersection of boundary dislocations of unlike signs that are known to prevail over screw ones under cryogenic deformation conditions [12, 13]. It is noteworthy that the plastic deformation resistance level achieved by drawing at $77 \mathrm{~K}$ to $e=0.92$, while maintaining the ductility of the iodide titanium, is the maximum possible and comparable to the strength of the low purity titanium [14, 15]. Analysis of the logarithmic damping decrement as a function of temperature that was measured in the present work, showed that cryogenic deformation up to $e_{1}$ and $e_{2}$ resulted in the wide peaks of the internal friction in the temperature range 100-175 K (Fig. 2). The deformation conditions have a considerable influence on the shape and height of the peaks. The internal friction peak after $77 \mathrm{~K}$ deformation to $e_{1}$ is substantially higher than that at $e_{2}$. This means that a higher concentration of linear and point defects is created in titanium at less true strain and maintained after storage at $300 \mathrm{~K}$. Consequently, the defect concentration decreases rather than increases with increasing true strain from $e_{1}$ to $e_{2}$. It causes nonmonotonous change in the microhardness and resistivity after the final stage of SPD by drawing to various true strains. However, the fact that there is no noticeable difference in the width of internal friction peaks for both true strains under cryogenic conditions (Fig. 2a) indicates that the type (spectrum) of point defects that is determined by the energy of
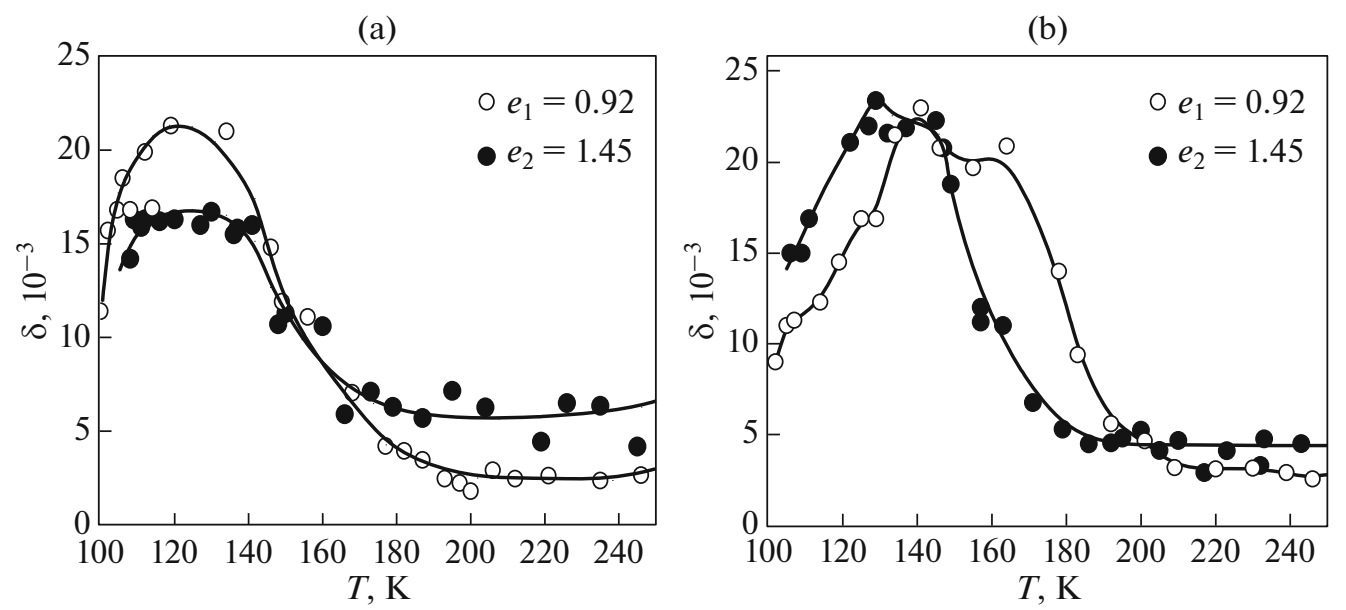

Fig. 2. Temperature dependencies of the internal friction of titanium deformed by drawing at (a) 77 and (b) $300 \mathrm{~K}$ to different true strains. 

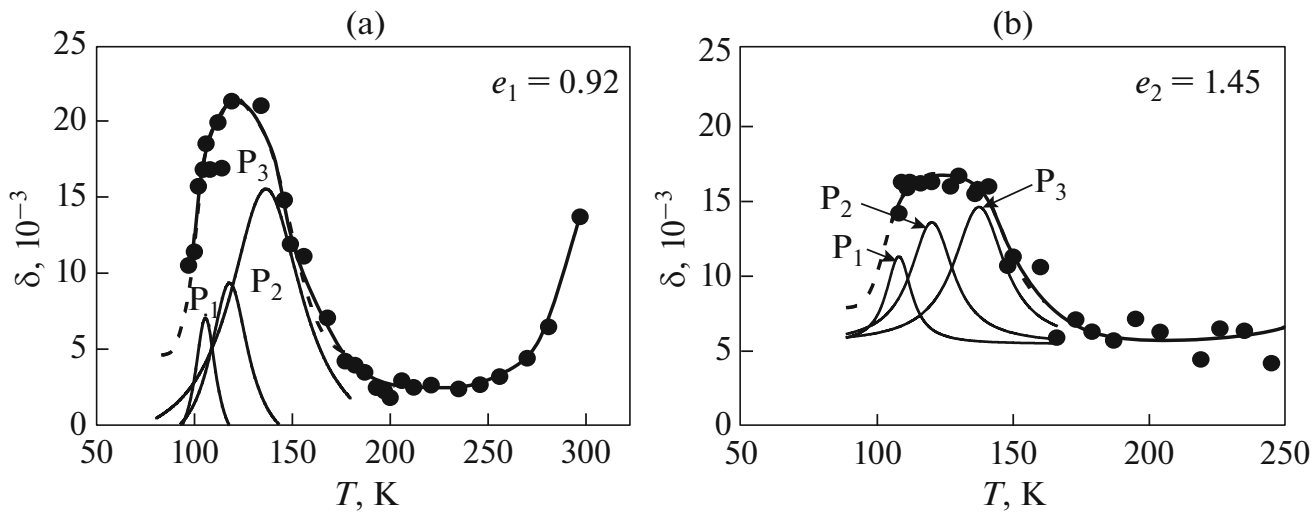

Fig. 3. Decomposition of the experimental temperature dependences of the internal friction in titanium into Debye peaks after drawing at $77 \mathrm{~K}$ to different true strains.

their bonding with dislocations, is independent of the true strain.

Let us analyze this assumption based on existing ideas about inelasticity phenomena in metals with a hcp lattice. Plastic deformation of such metals is known to change $\delta(T)$ in the temperature range 100$175 \mathrm{~K}$ and result in Hasiguti peaks that are caused by relaxation processes of interaction between linear and point defects (for example, the appearance and movement of double kinks on dislocations, as well as their interaction with point defects) $[17,18]$. The deformation by drawing resulted in wide Hasiguti peaks and therefore these peaks cannot be described by the relaxation time only. This peak shape may indicate the presence of several overlapping peaks with the same relaxation time on the temperature scale. When ana- lyzing Hasiguti peaks, they are usually decomposed into several Debye peaks [18, 19]. We found that each internal friction peak obtained after the decomposition of a wide peak is characterized by one activation energy that determines the interaction energy of a dislocation with different types of point defects. Three Debye internal friction peaks (Fig. 3) were formed as a result of the decomposition and the corresponding activation energies of each relaxation process were calculated. The results of the computer-aided calculation of the decomposition of the experimental $\delta(T)$ curves into the constituents and their corresponding activation energies estimated by Eq. (1) are listed in Table 1.

Analysis of the energy activation of the Debye peaks observed after the drawing suggests that the spectrum of point defects corresponds to the same

Table 1. Features of the Debye peaks of the internal friction in titanium deformed at 77 and $300 \mathrm{~K}$ to $e_{1}$ and $e_{2}$

\begin{tabular}{|c|c|c|c|c|}
\hline $\begin{array}{c}\text { Drawing } \\
\text { temperature, } \\
\mathrm{K}\end{array}$ & True strain $e$ & $\begin{array}{c}\text { Temperature of the peaks } \\
\text { after the decomposition } \\
\text { of the experimental } \\
\text { peaks, } \mathrm{K}\end{array}$ & $\begin{array}{l}\text { Activation energy } \\
\text { of the process, } \mathrm{eV}\end{array}$ & $\begin{array}{l}\text { Type of point defects that interact } \\
\text { with dislocations }[16-18]\end{array}$ \\
\hline 77 & $e_{1}=0.92$ & $\begin{array}{l}\mathrm{P}_{1}, 104 \\
\mathrm{P}_{2}, 116 \\
\mathrm{P}_{3}, 136\end{array}$ & $\begin{array}{l}0.27 \\
0.31 \\
0.36\end{array}$ & $\begin{array}{l}\text { Divacancies } \\
\text { Monovacancies } \\
\text { Vacancy-interstitial atom complex }(\mathrm{H}, \mathrm{O})\end{array}$ \\
\hline 77 & $e_{2}=1.45$ & $\begin{array}{l}\mathrm{P}_{1}, 110 \\
\mathrm{P}_{2}, 116 \\
\mathrm{P}_{3}, 137\end{array}$ & $\begin{array}{l}0.29 \\
0.31 \\
0.37\end{array}$ & $\begin{array}{l}\text { Divacancies } \\
\text { Monovacancies } \\
\text { Vacancy-interstitial atom complex }(H, O)\end{array}$ \\
\hline 300 & $e_{1}=0.92$ & $\begin{array}{l}\mathrm{P}_{1}, 114 \\
\mathrm{P}_{2}, 139 \\
\mathrm{P}_{3}, 166\end{array}$ & $\begin{array}{l}0.30 \\
0.37 \\
0.44\end{array}$ & $\begin{array}{l}\text { Divacancies } \\
\text { Vacancy-interstitial atom complex }(\mathrm{H}, \mathrm{O}) \\
\text { Vacancy-interstitial atom complex }(\mathrm{N}, \mathrm{C})\end{array}$ \\
\hline 300 & $e_{2}=1.45$ & $\begin{array}{l}\mathrm{P}_{1}, 111 \\
\mathrm{P}_{2}, 127 \\
\mathrm{P}_{3}, 146\end{array}$ & $\begin{array}{l}0.29 \\
0.34 \\
0.39\end{array}$ & $\begin{array}{l}\text { Divacancies } \\
\text { Vacancy-interstitial atom complex }(\mathrm{H}, \mathrm{O}) \\
\text { Vacancy-interstitial atom complex }(\mathrm{O}, \mathrm{N})\end{array}$ \\
\hline
\end{tabular}


processes, namely, interaction between dislocations and divacancies, and vacancies and vacancy-interstitial atom complexes.

Importantly, the height of the Debye peaks after cryogenic deformation to $e_{1}$ is greater than that after deformation to $e_{2}$ (Fig. 3). Therefore, the concentration of linear and point defects of different types is greater after a smaller cryogenic deformation $\left(e_{1}\right)$. This result explains the fact that the microhardness and electrical resistivity at $e_{1}$ are higher than those at $e_{2}$. It also confirms the previous assumption about the cause (due to the opening of microcracks or coalescence of vacancies in the monoatomic disks) of a sharp drop in the $H_{\mu}(e)$ and $\rho(e)$ dependencies after deformation to $e>e_{1}$.

A qualitatively different titanium structure forms during drawing at $300 \mathrm{~K}$ (Fig. 2b). In contrast to cryogenic deformation, the height of the internal friction peak after drawing at $300 \mathrm{~K}$ to $e_{2}$ is slightly higher than that after $e_{1}$. This means that the concentration of deformation defects increases with deformation, but insignificantly, which corresponds to a slight increase in the microhardness with increasing deformation (Fig. 1b). The experimental internal friction peaks that were obtained after deformation at $300 \mathrm{~K}$, were similarly decomposed into Debye peaks and the corresponding activation energy of relaxation processes calculated for the interaction of dislocations with one type of point defects confirmed that processes with a higher activation energy of dislocation interaction with point defects develop at a lower true strain $\left(e_{1}\right)$ than those at a higher true strain $\left(e_{2}\right)$. However, the difference in these energies is not significant (see Table 1). This can result from the interaction between dislocations and vacancy-interstitial atom complexes of different impurities $(\mathrm{H}, \mathrm{O}, \mathrm{N}, \mathrm{C})$ with different atomic radii and, therefore, creating different levels of internal stresses. An internal friction peak at $166 \mathrm{~K}$ after $300 \mathrm{~K}$ deformation to $e_{1}$ that is missing after other deformation treatments, attracts attention. The activation energy $(0.44 \mathrm{eV})$ indicates that this peak seems to be related to screw dislocations. An increase in the deformation to $e_{2}=1.45$ causes the peaks to shift towards low temperatures, i.e., the peak at $166 \mathrm{~K}$ with higher activation energy disappears. An analysis of the activation energy of the internal friction peaks suggests that the number of screw dislocations, edge dislocations, and edge dislocation-point defect complexes decreases significantly at $e_{2}=1.45$. Point defects responsible for the peak formation can be both deformation-generated vacancies and impurity atoms such as hydrogen [20]. Importantly, the height and the shape of the internal friction peak of titanium deformed at $300 \mathrm{~K}$ to $e_{2}=1.45$ coincides with those of titanium deformed at $77 \mathrm{~K}$ to $e_{1}=0.92$. The effect of increasing the deformation degree at $300 \mathrm{~K}$ on the peak shape is similar to that of decreasing the defor- mation temperature to $77 \mathrm{~K}$. This fact is of practical importance because if the final sizes of the product is limited (e.g., wire diameter), the nanostructure state can be achieved even after small degrees of deformation by drawing, but under low-temperature (cryogenic) conditions.

\section{CONCLUSIONS}

The experimental temperature dependences of the low-frequency internal friction $\delta(T)$ for the iodide titanium allow us to draw the following conclusions.

(1) The maximum level of strength was achieved at the final stage of SPD by drawing at $77 \mathrm{~K}$ at small strain levels $(0.5<e<0.9)$. The SPD was implemented by a sequential combination of the deformation techniques that provide different stress epures (compression-squirting-extrusion-drawing).

(2) An analysis of the energy activation of the interaction between point defects and dislocations suggests that the spectrum of point defects formed by drawing at $77 \mathrm{~K}$ to various true strains corresponds to the same processes, namely, interaction between dislocations and divacancies, and vacancies and vacancy-interstitial atom complexes.

\section{REFERENCES}

1. R. Z. Valiev and I. V. Aleksanrov, Nanostructured Materials, Obtained by Intensive Plastic Deformation (Logos, Moscow, 2000) [in Russian].

2. Ya. E. Bel'geizimer, D. F. Orlov, D. V. Synkov, and A. V. Reshetov, "Screw pressing: technological aspects," Fiz. Tekh. Vys. Davlenii 12, 40-46 (2002).

3. R. R. Mulyukov, R. M. Imaev, A. A. Nazarov, M. F. Imaev, and V. M. Imaev, Superplasticity of Ultrafine Alloys: Experiment, Theory, Technologies (Nauka, Moscow, 2014) [in Russian].

4. V. K. Aksenov, N. F. Andrievskaya, O. I. Volchok, M. M. Oleksienko, Ya. D. Starodubov, and M. A. Tikhonovskii, "Microstructure and physicomechanical properties of a natural $\mathrm{Cu}-\mathrm{Nb}$ composite after drawing at 77 K," Metallogizika 13, 24-28 (1991).

5. O. V. Chernyi, G. E. Storozhilov, N. F. Andrievskaya, V. O. Ilicheva, Ya. D. Starodubov, O. I. Volchok, L. A. Chirkina, M. B. Lazareva, and M. B. Okovit, "Structure and properties of differently directed deformed niobium-titanium alloy," IEEE Trans. Appl. Supercond. 15, 3502-3505 (2005).

6. M. A. Tikhonovskii, I. F. Kislyak, O. I. Volchok, T. Yu. Rudycheva, V. G. Yarovoi, A. V. Kuz'min, N. V. Kamyshanchenko, and I. S. Nikulin, "Physicomechanical properties of titanium after severe plastic deformation by drawing under cryogenic $(77 \mathrm{~K})$ conditions," Fiz. Tekh. Vys. Davlenii 18, 96-99 (2005).

7. I. M. Neklyudov, O. I. Volchok, V. V. Kalinovskii, V. S. Okovit, V. I. Sokolenko, P. A. Khaimovich, N. A. Chernyak, and L. A. Chirkina, "Effect of a combination of deformations at $77 \mathrm{~K}$ by drawing and quasihydroextrusion on the physical and mechanical properties and structural state of $06 \mathrm{Kh} 16 \mathrm{~N} 15 \mathrm{M} 3 \mathrm{~B}$ steel," 
Vopr. At. Nauki Tekh., ser.: "Vakuum, chistye metally, sverkhprovodniki", No. 1, 108-114 (2008).

8. K. V. Kutniy, O. I. Volchok, I. F. Kislyak, M. A. Tikhonovsky, and G. E. Storozhilov, "Obtaining of pure nanostructured titanium for medicine by severe deformation at cryogenic temperatures," Materialwissenschaft und Werkstofftechnik. 42, 114-117 (2011).

9. G. E. Storozhilov, N. F. Andrievskaya, and M. A. Tikhonovskii, "Diffusional decomposition of a strongly deformed Nb-Ti alloy," Phys. Met. Metallogr. 115, 710715 (2014).

10. O. I. Volchok, I. M. Neklyudov, and Ja. D. Starodubov, "Effects of cryogenic deformation on hardening of 06Kh16N15M3D steel,” Cryogenics, ICMC Suppl. 32, 114-116 (1992).

11. K. Wert and I. Marx, "A new method for determining the heat of activation for relaxation processes," Acta Metall., No. 1, 113-115 (1953).

12. I. A. Gindin, Ya. D. Starodubov, and V. K. Aksenov, "Structure and strength properties of metals with an extremely distorted crystal lattice," Metallofizika 2, 4967 (1980).

13. I. A. Gindin, O. I. Volchok, and V. K. Aksenov, "Influence of sonication temperature and material purity on acoustic hardening," Fiz. Met. Metalloved. 48, 641646 (1979).

14. M. A. Shtremel, Strength of Alloys. Lattice Defects (Metallurgiya, Moscow, 1982) [in Russian].

15. B. A. Kolachev, Physical Metal Science of Titanium (Metallurgiya, Moscow, 1976) [in Russian].

16. L. T. Miyada-Naborikava and R. De Batist, "Effect of plastic deformation at $8 \mathrm{~K}$ on the damping spectrum of zirconium.," J. Phys. 44 9-651-9-656 (1983).

17. S. Okuda and R. R. Hasiguti, "Internal friction peaks of cold worked gold and copper," Acta Metall. 11, 257265 (1963).

18. A. Novik and B. Beri, Relaxation Phenomena in Crystals (Atomizdat, Moscow, 1975).

19. I. S. Golovin, T. S. Pavlova, S. B. Golovina, H. R. Sinning, and S. A. Golovin, "Effect of severe plastic deformation on internal friction of an $\mathrm{Fe}-$ at $\% \mathrm{Al}$ alloy and titanium," Mater. Sci. Eng., A 442, 165169 (2006).

20. H. Numakura, Y. Minonishi, and M. Koiwa, "Internal-friction and electron microscopy studies of coldworked single-crystal and polycrystalline titanium," Philos. Mag. A 63, 785-792 (1991).

Translated by T. Gapontseva 